\title{
Liquid Feedstock Plasma Spraying: An Emerging Process for Advanced Thermal Barrier Coatings
}

\author{
Nicolaie Markocsan ${ }^{1} \cdot$ Mohit Gupta $^{1} \cdot$ Shrikant Joshi $^{1} \cdot$ Per Nylén $^{1} \cdot$ \\ Xin-Hai $\mathbf{L i}^{2} \cdot$ Jan Wigren ${ }^{3}$
}

Submitted: 16 December 2016/in revised form: 9 March 2017/Published online: 15 May 2017

(c) The Author(s) 2017. This article is an open access publication

\begin{abstract}
Liquid feedstock plasma spraying (LFPS) involves deposition of ultrafine droplets of suspensions or solution precursors (typically ranging from nano- to submicron size) and permits production of coatings with unique microstructures that are promising for advanced thermal barrier coating (TBC) applications. This paper reviews the recent progress arising from efforts devoted to development of high-performance TBCs using the LFPS approach. Advancements in both suspension plasma spraying and solution precursor plasma spraying, which constitute the two main variants of LFPS, are presented. Results illustrating the different types of the microstructures that can be realized in LFPS through appropriate process parameter control, model-assisted assessment of influence of coating defects on thermo-mechanical properties and the complex interplay between pore coarsening, sintering and crystallite growth in governing thermal conductivity are summarized. The enhancement in functional performances/lifetime possible in LFPS TBCs with multilayered architectures and by incorporating new pyrochlore chemistries such as gadolinium zirconate, besides the conventional single $8 \mathrm{wt} . \%$ yttria-stabilized zirconia insulating ceramic layer, is specifically highlighted.
\end{abstract}

Keywords advanced thermal barrier coatings · columnar microstructure - liquid feedstock plasma spraying .

lifetime $\cdot$ porosity $\cdot$ thermal conductivity

Nicolaie Markocsan

nicolaie.markocsan@hv.se

University West, Trollhättan, Sweden

2 Siemens Industrial Turbomachinery, Finspång, Sweden

3 GKN Aerospace, Trollhättan, Sweden

\section{Introduction}

Increased functional and environmental demands on today's gas turbines require improved TBCs that are capable of withstanding the higher operating temperatures necessary to meet the incessant drive toward enhanced process efficiency. A $1 \%$ increase in engine efficiency of a medium sized power plant of $300 \mathrm{MW}$ results in estimated savings of more than $\$ 2 \mathrm{M} / \mathrm{year}$ in fuel costs and approximately 25,000 t/year reductions in $\mathrm{CO}_{2}$ emissions (Ref 1). Consequently, even small improvements on the above front result in huge benefits to both end-users and environment. However, such advanced TBCs demand new morphologies/microstructures and/or new materials and have constituted the focus of several recent research efforts.

Conventional TBCs have been typically composed of a duplex material system, comprising a ceramic topcoat and an intermetallic bond coat, deposited over a suitable hightemperature capable Ni-based superalloy. The function of the topcoat is to provide thermal insulation, while the role of the bond coat is to impart oxidation/corrosion protection besides enhanced adhesion of the topcoat to the metallic substrate. Yttria-stabilized zirconia (YSZ) is the most commonly used topcoat material due to its low thermal conductivity, high sintering and erosion resistance, relatively high coefficient of thermal expansion and good fracture toughness, to go with its high temperature stability.

The lifetime of a TBC is primarily related to its ability to survive the harsh working conditions prevailing in an engine that requires it to resist severe thermal cycling for long periods of time. Although thermal barrier systems exhibit varied failure mechanisms depending upon the operating conditions, a strain tolerant ceramic layer is known to provide excellent thermal cycling durability. The 
TBCs also need to resist sintering in order to preserve the strain tolerance and thermal insulation properties over time (Ref 2). Both the above characteristics can be controlled through proper design of the coating microstructure. It has been found that coatings with large globular pores and connected cracks through the coating microstructure can potentially yield both strain tolerance and low thermal conductivity (Ref 3 ). One of the methods to produce such coatings is by atmospheric plasma spraying (APS) employing a mixture of a ceramic material and a pore former as feedstock (Ref 4). Although early TBC research had suggested that an optimum level of porosity in the ceramic layer can ensure good strain tolerance of the coating without promoting excessive bond coat degradation, the microstructures that are now acknowledged to yield best strain tolerance are those with a columnar structure or high density of vertical cracks which ensure better compliance of the coating with the metallic substrate under cyclic thermal loads (Ref 5). The electron beam physical vapor deposition (EB-PVD) process is commonly used today to produce columnar TBCs but the high cost of the process and high effective thermal conductivity of the deposited coatings are significant drawbacks (Ref 6). The more recently developed spraying processes that use a liquid feedstock instead of a conventional powder have demonstrated great potential to produce TBCs with a columnar or vertically cracked microstructure (Ref 7). As these coatings are also characterized by high porosity, their thermal conductivity is typically lower than the thermal conductivity of the state-of-the-art APS and EB-PVD coatings, thereby providing an added benefit (Ref 8).

The higher operating temperatures essential to enhance engine efficiency also demand new materials for TBCs. Materials such as pyrochlores, perovskites, rare earth garnets have been explored in recent times and found to be capable of withstanding temperatures above $1200{ }^{\circ} \mathrm{C}$ (which is the upper limit of the current YSZ TBCs) (Ref 9). Although these materials usually exhibit lower toughness and thermal expansion coefficient as compared to YSZ, this provides encouragement to explore multilayer TBC architectures, with the different layers synergistically combining to fulfill all the requirements of a durable, low thermal conductivity protection system for high-temperature operation.

This article briefly highlights the activities in the field of advanced TBCs undertaken by the authors, with use of porosity formers and liquid feedstock to engineer desired microstructures. Both main variants of the LFPS approach, namely suspension plasma spraying (SPS) and solution precursor plasma spraying (SPPS), are discussed. Novel multilayer architectures involving new TBC materials are also presented.
High-Performance Strain Tolerant TBC's by APS

Thermal sprayed coating microstructures are inherently highly heterogeneous, consisting of distinct features such as pores and cracks of different sizes. The size and shape of these features determines the coating's thermal and mechanical properties and also significantly influences the service lifetime of these coatings (Ref 10). Therefore, in order to achieve a high-performance TBC with low thermal conductivity, high strain tolerance and long lifetime, optimization of the coating microstructure is essential. Determination of parametric impact on coating microstructure, as well as optimization of the spray conditions, is usually accomplished through a design of experiments approach. However, this still demands significant experimentation, both in terms of spraying and characterization, and does not necessarily provide fundamental understanding. On the other hand, simulation techniques are advantageous to quantify microstructure-property relationships as well as to develop and analyze new coating designs (Ref 11).

Previous work from this group has shown that coatings with large globular pores and connected cracks through the coating microstructure result in improved strain tolerance and lower thermal conductivity than conventional APS TBCs (Ref 12). One method to produce such coatings by APS involves using a feedstock powder that is a mixture of a ceramic material and a pore former. This is a promising way of ensuring that the thermal conductivity is low (due to the ceramic material and because of the presence of big pores generated by the pore former) and the coating cohesion is good, since standard spray parameters can be used for spraying the TBC (Ref 4). The high porosity (around 25\%) provides enhanced strain tolerance and, thus, improved lifetime of the coating. Yet another method to produce similar microstructures is to dispense with the pore former but employ spray parameters with very low power and long spray distance to promote generation of highly porous coatings (Ref 11). However, the deposition efficiency is considerably reduced in this case due to only partial melting of the particles during spraying. Figure 1 shows the microstructures using these two methods where the large globular pores with connected cracks are indicated by arrows.

A fundamental understanding of the influence of large globular pores and connected cracks on thermal-mechanical properties of the coating can be achieved with the help of modeling. This can be done by artificially separating the different microstructural features and analyzing their individual influence on coating properties. Figure 2 shows the microstructure images created artificially with a microstructure generator modeling software Tbctool (Onera, France) representing only pores, free cracks with pores 
(a)
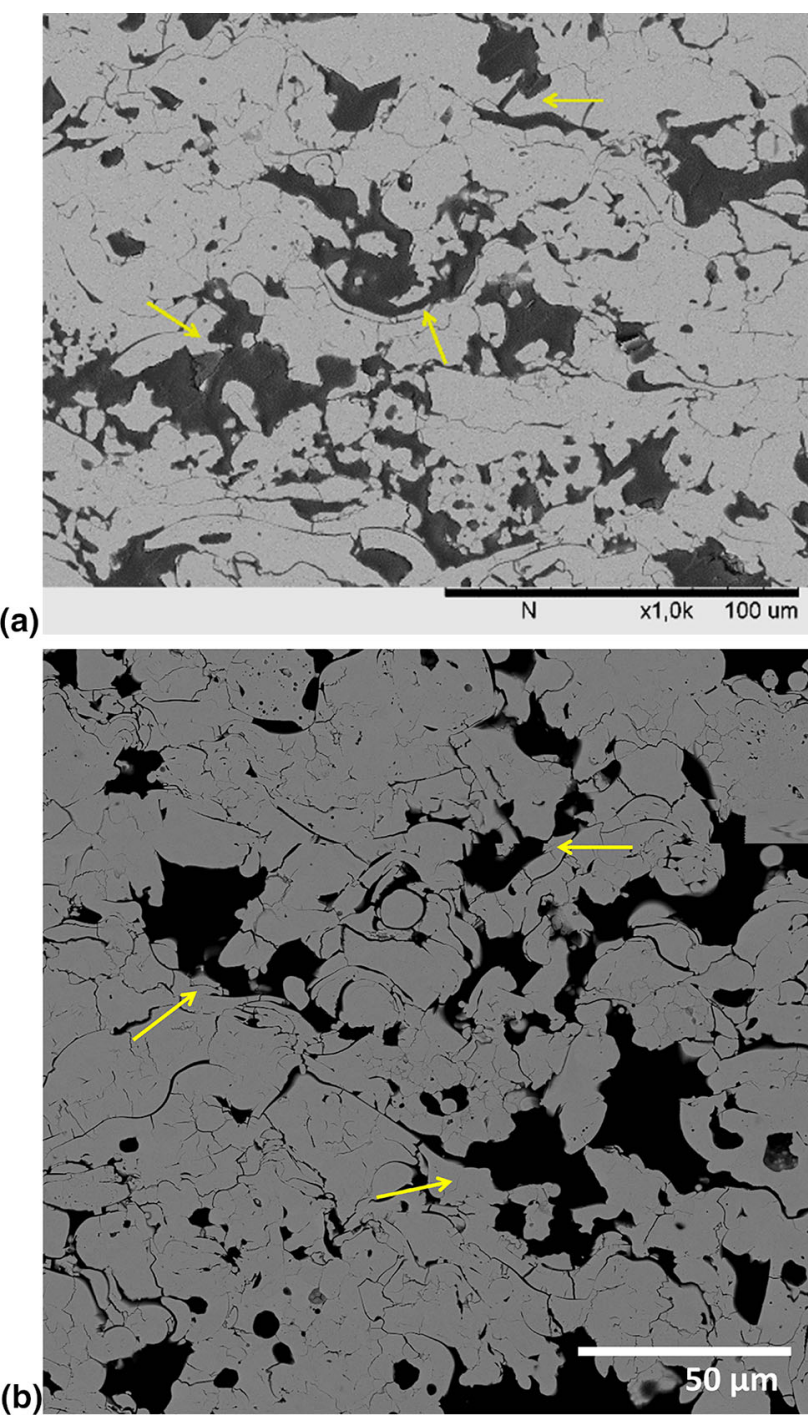

Fig. 1 High-performance topcoat microstructure achieved by (a) using pore formers in feedstock and (b) optimizing spray parameters (Ref 11)

and connected cracks with pores. Tbctool generates artificial microstructure images through statistical representation of different microstructural features such as globular pores and free cracks obtained from a library within the software built with features extracted from real SEM images. The images generated by Tbctool shown in Fig. 2 represent a total coating porosity similar to that depicted in Fig. 1. These images were analyzed by finite element modeling, and it was found that the image shown in Fig. 2(c) results in lowest thermal conductivity and lowest Young's modulus as compared to the other two images (Ref 12). These results show that large globular pores with connected cracks are essential for a high-performance $\mathrm{TBC}$, and merely increasing porosity by introducing large pores may not be adequate to ensure superior coating performance.

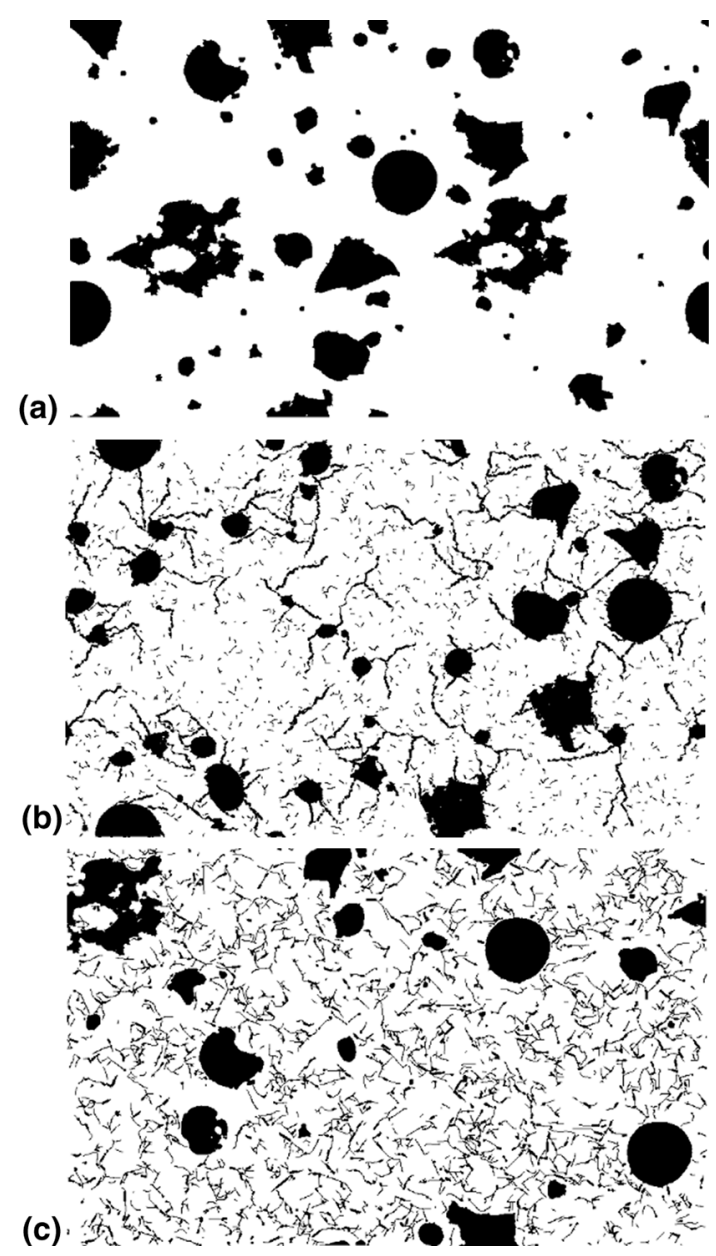

Fig. 2 Microstructure images created artificially by modeling representing (a) only pores, (b) free cracks with pores and (c) connected cracks with pores (Ref 12)

\section{Suspension Plasma Spraying}

The limitation of minimum particle size in conventional APS process employing powder feedstock has motivated the development of new plasma spray approaches based on using liquid feedstock in the form of either suspensions or solution precursors. The suspensions typically used in SPS are either based on water or an organic solvent, with the powder particles being in the nano- or sub-micrometric size range.

It is well known that the TBC microstructure has a major bearing on its functional properties. As the particles comprising the suspensions are much smaller than in case of conventional powder feedstock (nano-metric or submicrometric size range in the former, compared to tens of microns in the latter), the mechanisms that control microstructure formation in SPS are more complex than in APS (Ref 13). Fauchais et al. (Ref 14) observed that coating formation in SPS is related to the generation of very fine droplets due to atomization or fragmentation of 
the suspension after injection, resulting in small in-flight particles once the solvent has evaporated. The particles follow the gas stream's trajectory, stick on the side of the asperities on the substrate surface to enable both lateral and vertical growth, and as spraying proceeds, they contribute solely to vertical growth of the coating. This complex interplay can result in a columnar-like microstructure under specific conditions of spraying (Ref 15). The deflection of the particle on impact depends on the Stokes number. Berghaus et al. (Ref 16) have noted that the momentum of the particle at impact is crucially important and, thus, the particle velocity, particle size and material density are among the factors that strongly influence microstructure formation, including pore shape and size. Ganvir et al. (Ref 17) revealed the strong dependence of particles' in-flight characteristics on the spray parameters which, in turn, influence coating formation and microstructure. Using an axial suspension plasma spray gun, the authors in Ref 17 identified four distinct types of microstructures which were further correlated with the spray parameters used for deposition. Apart from the vertically cracked TBCs, the columnar microstructures were classified as porous, feathery and columnar as presented in Fig. 3 (Ref 17). In Table 1, the key spray parameters that influence the microstructures presented in Fig.3 are highlighted (Ref 17). More details about the process conditions are given in Ref 17.
The SPS coatings exhibit different microstructural features such as vertical cracks, spacing between columns (inter-columnar spacing), inter-pass porosity bands, branching cracks, etc. At higher magnifications, coatings also show features such as fine (sub-micrometric or nanometric) pores, which may be either interconnected or isolated. These different features are marked in Fig. 3.

Figure 4 shows a comparative distribution of fine pores $\left(<1 \mu \mathrm{m}^{2}\right)$ and coarse pores $\left(>1 \mu \mathrm{m}^{2}\right)$ in five samples sprayed on similar substrate specimens and with identical feedstock materials but with different spray parameters. The suspension used was 8YSZ (INNOVNANO, Coimbra, Portugal) with $\mathrm{d} 50=492 \mathrm{~nm}$ and a solid loading of $25 \mathrm{wt} . \%$ powder in ethanol. The process parameters employed for producing the coatings are presented in Table 2 (Ref 18).

The microstructural features, such as the extent of fine and coarse porosity and column density are governed by the deposition conditions employed (Ref 18). These features also undergo changes upon prolonged thermal exposure though in different manners as shown in Fig 4(a) and (b). All coatings, except Exp4, revealed an increase in the coarse porosity after heat treatment that can be primarily attributed to widening or opening up of the inter-columnar spaces. In Exp4, the inter-columnar spacing did not change but sintering of the coarse pores within the columns was observed, which led to a decrease in the coarse porosity (Ref 18). In contrast, the impact of heat treatment on the

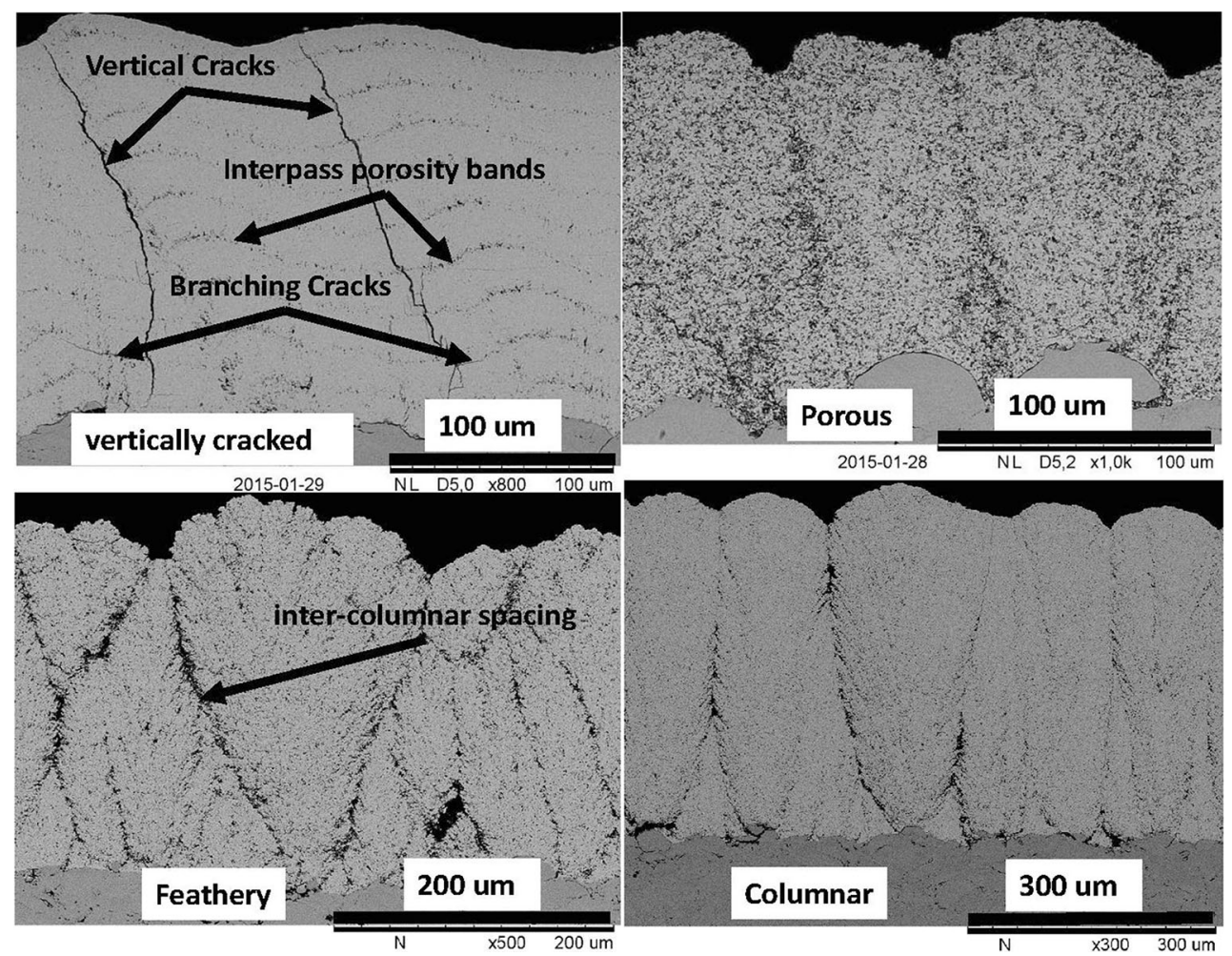

Fig. 3 Typical microstructures produced by SPS (Ref 17) 
Table 1 Influence of process parameters on microstructure formation (Ref 17)

\begin{tabular}{lclcccc}
\hline Coating name & Microstructure & Gas flow & Spray distance & Surface speed & Feed rate & Current \\
\hline Porous & Low & Low & High & High & Low \\
Vertically cracked & High & Low & Low & High & High \\
Feathery & High & High & Low & Low & High \\
Columnar & & & & & & \\
\end{tabular}

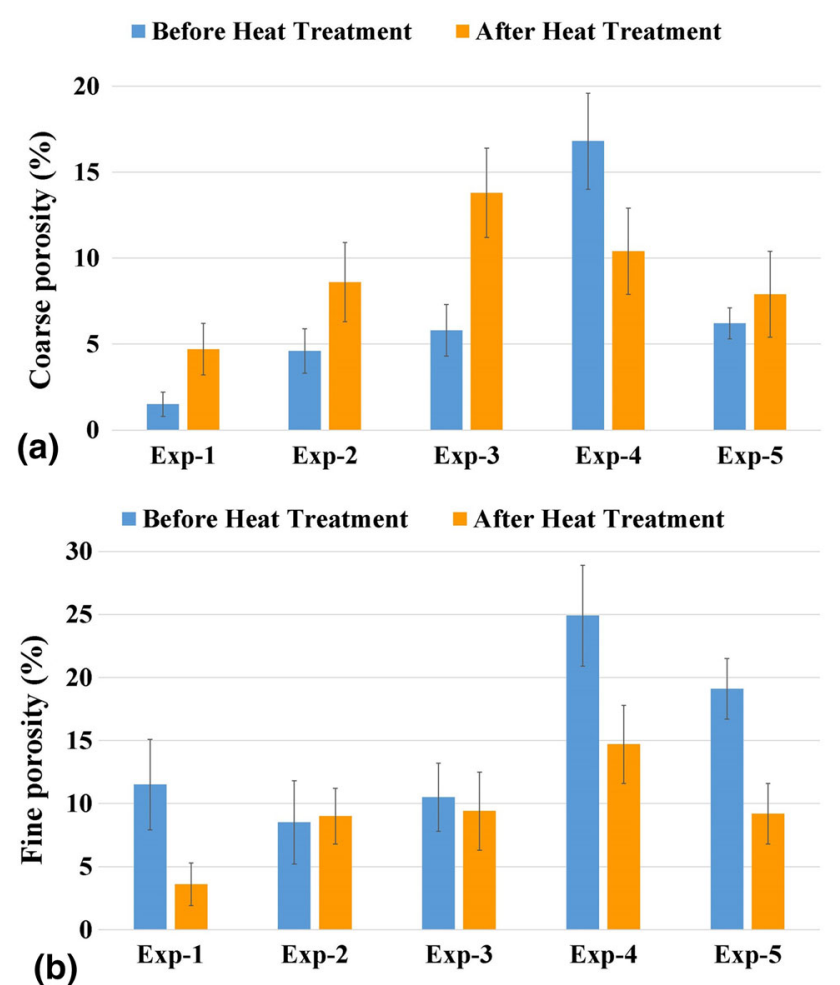

Fig. 4 Quantification of (a) coarse porosity and (b) fine porosity by image analysis technique before and after isothermal heat treatment (Argon at $1150^{\circ} \mathrm{C}$ for $200 \mathrm{~h}$ ) (Ref 18) fine porosity was that it either decreased (in case of Exp1, Exp4 and Exp5) or remained virtually constant within the range of the error bars (in case Exp2 and Exp3). The overall decrease in fine porosity is suggestive of pores tending to get finer or closing due to sintering effect (Ref 18).

The microstructural features in a TBC also influence its thermal properties. In Fig. 5, the thermal conductivity of the various samples presented in Fig. 4 is shown. The thermal conductivity was measured by laser flash analysis and found, as expected, to be lowest in coatings exhibiting highest porosity. The coatings studied in this work (Ref 18) were found to respond differently to heat treatment, particularly in terms of the effect on thermal conductivity. The thermal conductivity following heat treatment was found to either increase or decrease, and in some coatings it even remained unchanged. The most interesting results were from Exp3 that showed a significant decrease in thermal conductivity (Fig. 5). The exact reason for this apparent lack in trend clearly needs further investigation but the authors in Ref 18 have attributed it to the trade-off between the three microstructural changes noted after heat treatment, namely pore coarsening, sintering and crystallite size growth. It is known that the more the scattering interfaces, the higher the phonon scattering and hence the lower the thermal conductivity. Pore coarsening, which increases the overall porosity, can cause a decrease in thermal
Table 2 Process parameters used for production of all five types of coatings presented in Fig. 4 and 5 (Ref 18)

\begin{tabular}{llllll}
\hline Process parameter & \multicolumn{4}{c}{ Specimen nomenclature } \\
\cline { 2 - 5 } & Exp1 & Exp2 & Exp3 & Exp4 & Exp5 \\
\hline Spray distance $(\mathrm{mm})$ & 75 & 50 & 100 & 100 & 100 \\
Surface speed $(\mathrm{cm} / \mathrm{s})$ & 145.5 & 75 & 75 & 216 & 216 \\
Suspension feed rate $(\mathrm{mL} / \mathrm{min})$ & 70 & 45 & 45 & 100 & 45 \\
Total gas flow rate $(\mathrm{L} / \mathrm{min})$ & 250 & 200 & 300 & 300 & 200 \\
Total power during spray $(\mathrm{kW})$ & 125 & 101 & 124 & 124 & 116 \\
Total enthalpy during spray $(\mathrm{kJ})$ & 13 & 11.2 & 12.5 & 12.5 & 11.2 \\
\hline
\end{tabular}


conductivity; sintering, on the other hand, decreases the porosity and hence can increase the thermal conductivity. Crystallite size growth, which reduces the grain boundary interfaces, can also lead to an increase in the thermal conductivity. Thus, it is envisioned that a complex interplay between the role of heat treatment on the above microstructural attributes eventually governs its influence on thermal conductivity.

Apart from the spray parameters influencing the coating microstructure as discussed above, Curry et al. have shown that bond coat roughness, too, has a direct influence on the column density (Ref 19). Figure 6 shows that, as the roughness of the bond coat increases, the columns' density in TBCs decreases. This observation relates well to the

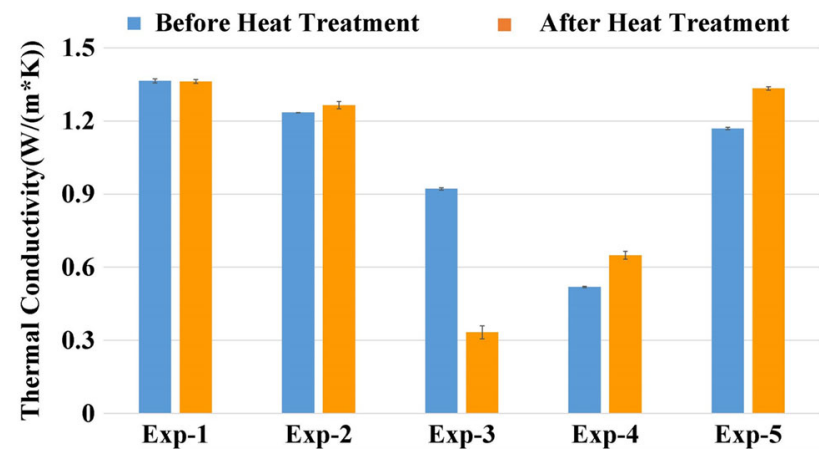

Fig. 5 Thermal conductivity results of various SPS coatings before and after heat treatment (Ref 18) above proposed deposition mechanism in SPS (Ref 15). Thus, the individual columns form by progressive build-up of particulates on surface peaks. Reducing surface roughness will increase the density of peaks in a specific area. As each peak is a possible initiation site for a column within the SPS coating, smoother surfaces tend to generate a greater number of columns. Rough surfaces have fewer peaks though they are larger in size. This results in a more uneven SPS layer dominated by larger columns (Ref 19). It should be emphasized that all four samples presented in Fig. 6 were sprayed under similar conditions, with only the bond coat roughness being altered in different ways as indicated in the figure.

The chemistry of the bond coat as well as the particle size of the bond coat powder feedstock also plays an important role in determining the functional properties of SPS TBCs. As illustrated in Fig. 7, when different compositions and particle sizes were used for spraying the bond coats (with all other spray parameters, ceramic topcoat material and test conditions remaining identical), the thermal cyclic life of the samples was found to vary significantly (Ref 20).

\section{New Materials and Multilayered Systems}

Due to the known drawbacks of YSZ above $1200{ }^{\circ} \mathrm{C}$, such as decomposition into high yttria and low yttria phases, significant sintering, the search for new TBC materials
Fig. 6 Influence of bond coat roughness on column density (Substrate: Hastelloy X, Bond coat: AMDRY 386, sprayed by APS, F4 gun, topcoat: 8 YSZ suspension, 10wt.\% solid load, sprayed with Mettech Axial III gun) (Ref 19]
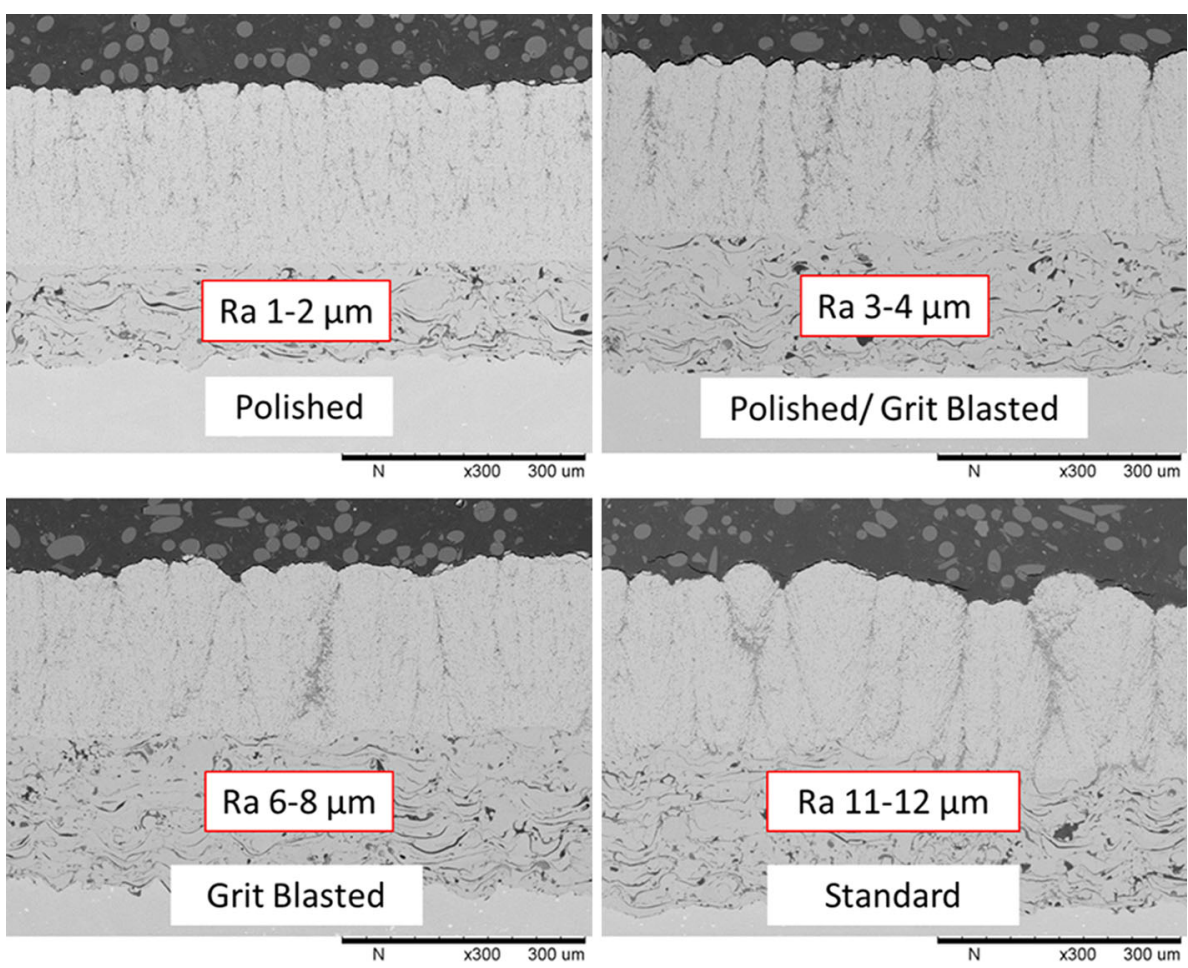
without compromising requirements such as sintering resistance, phase stability, thermal conductivity, oxidation resistance and CMAS penetration resistance has been a subject of considerable research interest. Pyrochlores are promising for fulfilling the above requirements at higher temperatures (Ref 21-24). Among the pyrochlores, gadolinium zirconate $\left(\mathrm{Gd}_{2} \mathrm{Zr}_{2} \mathrm{O}_{7}\right)$ and lanthanum zirconate $\left(\mathrm{La}_{2} \mathrm{Zr}_{2} \mathrm{O}_{7}\right)$ are interesting candidates, although the latter is difficult to process due to the tendency for $\mathrm{La}_{2} \mathrm{O}_{3}$ to evaporate and result in loss of desired stoichiometry (Ref 25, 26). Gadolinium zirconate (GZ) has excellent phase stability and lower bulk thermal conductivity than YSZ. It has also been shown that GZ is capable of more effectively inhibiting the penetration of CMAS than the YSZ system (Ref 27). However, it has a lower fracture toughness (Ref 28-30) and also a tendency to react with and degrade the alumina that forms on the bond coat as the protective thermally grown oxide (TGO) above $1200{ }^{\circ} \mathrm{C}$ (Ref 31).

In order to overcome these drawbacks, a multilayered approach with GZ on top of YSZ has been proposed (Ref 32-34). APS-deposited double-layer GZ/YSZ coating has already been shown to yield higher thermal cycling life compared to single-layer YSZ (Ref 35). The functional performance of such a system has been evaluated and compared with single-layer 8YSZ coatings (Ref 36-38). Both coating systems were deposited using SPS. Additionally, a triple-layer TBC comprising a relatively denser $30-\mu$ m-thick GZ layer on top of a GZ/YSZ TBC was deposited by SPS in order to impart better erosion and CMAS attack resistance. The three different coating architectures investigated are shown in Fig. 8.

Thermal conductivity, thermal cyclic life and erosion resistance of the three different TBC designs were compared. The as-sprayed TBCs were subjected to thermal cyclic fatigue test at $1100{ }^{\circ} \mathrm{C}$ and $1200{ }^{\circ} \mathrm{C}$. Also, the thermal conductivity of as-sprayed TBCs was measured in the temperature range of $25{ }^{\circ} \mathrm{C}$ to $1000{ }^{\circ} \mathrm{C}$. The results revealed that the GZ-based multilayered TBCs had a higher thermal cyclic life and lower thermal conductivity compared to single-layer YSZ TBC, with the life enhancement in the thermal cyclic tests carried out at $1300{ }^{\circ} \mathrm{C}$ being significant (43 cycles in case of YSZ compared to 395 and 521 cycles for the double- and triple-layer TBCs discussed above (Ref 39)). Erosion tests at room temperature were also carried out on the TBCs. Among the as-sprayed TBCs, double-layer GZ/YSZ exhibited lowest erosion resistance. The triple-layer GZ dense/GZ/YSZ TBC had a slightly better erosion resistance than the double-layer TBC due to the presence of relatively denser GZ on top. In this context, it is relevant to mention that, in the case of EB-PVD TBCs, gadolinia doping has been found yield a lower high temperature erosion rate (Ref 40). The study showed that columnar microstructure to mimic the EB-PVD process can be created in both single- and double-layer TBCs by SPS, and a dense third layer also deposited on top of the columnar coatings. It may be mentioned that such

Fig. 7 TCF lifetime of various 8 YSZ SPS TBCs sprayed on bond coats with varying chemistry and particle size
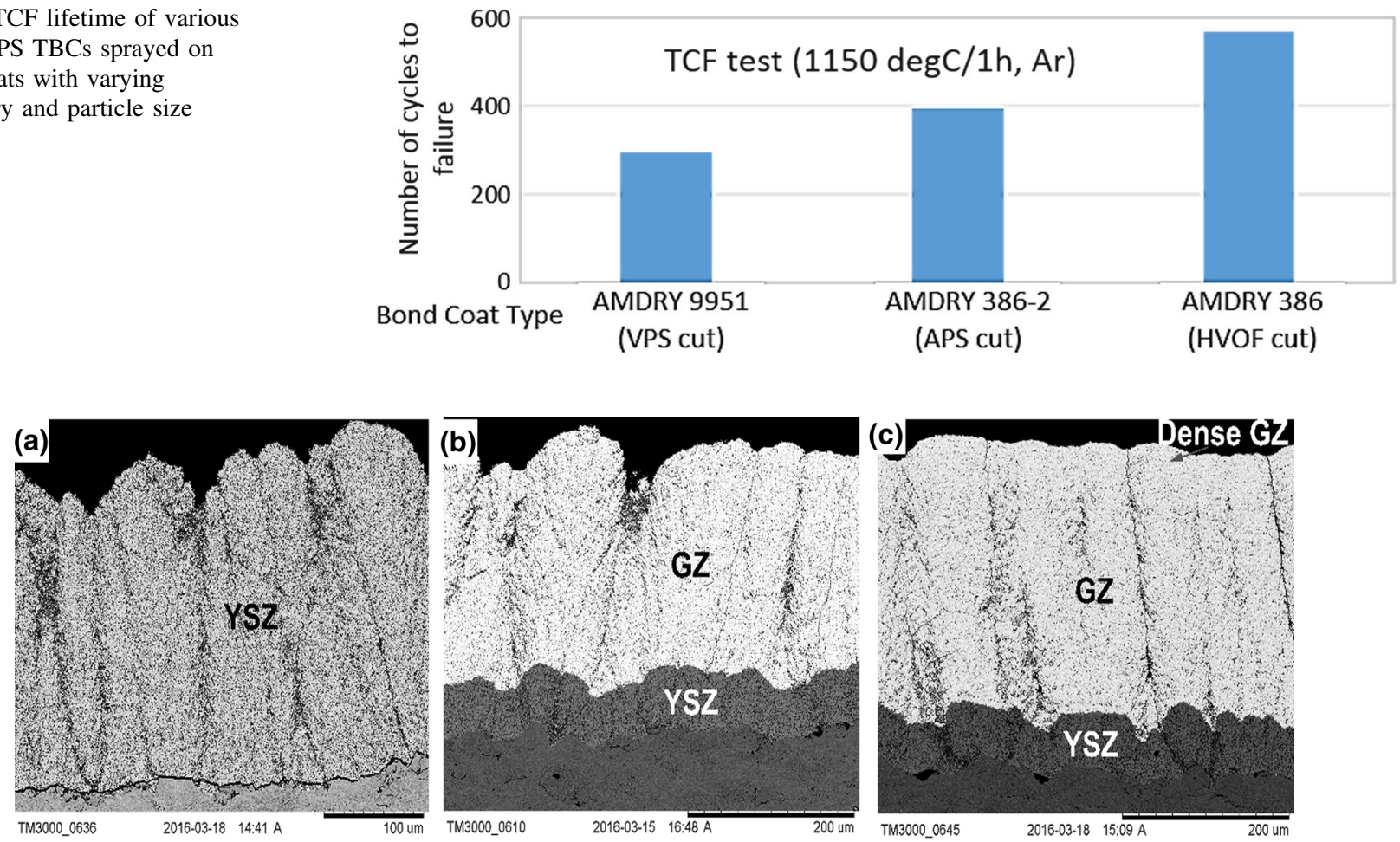

Fig. 8 Architectures of the three different TBCs studied, (a) single-layer YSZ, (b) double-layer YSZ/GZ, (c) triple-layer YSZ/GZ/Dense GZ 

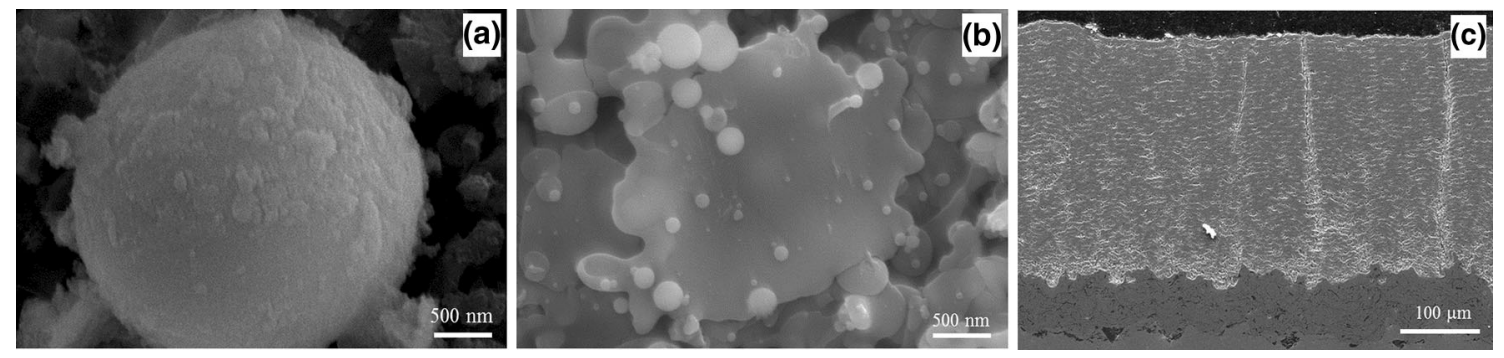

Fig. 9 Typical SPPS characteristics: (a) in-flight generated particles, (b) single particle splat and (c) vertically cracked microstructure obtained with a $24 \mathrm{ml} / \mathrm{min}$ zirconium acetate + yttrium nitrate

conceptually similar bilayer coating approaches have also been evaluated in the past, although not by SPS route, and bear considerable promise to engineer through-thickness microstructure and mechanical properties for enhanced durability and superior performance (Ref 41,42 ).

\section{Solution Precursor Sprayed TBC}

Similar to the SPS technique discussed above, the SPPS method has also been the subject of considerable research interest in recent times due to the several inherent advantages that this route offers (Ref 43-45). The SPPS method relies on the use of suitable solution precursors that generate particles of the desired coating material in situ and, thereby, provides the added benefit over SPS of obviating the need for expensive nano- or submicron sized powder feedstock. While this is a major attraction, the SPPS process is also more complex to control/optimize and has consequently not been investigated as widely as the SPS. Prior work has shown the SPPS coatings to possess interesting intrinsic features like vertical cracks, homogenous fine pore structure, splats that are an order of magnitude smaller than in conventional APS as well as greater durability under thermal cycling conditions (Ref 46, 47).

As in case of SPS, the relevant properties of SPPS TBCs in terms of strain tolerance, thermal conductivity, longevity under thermal cycling conditions, etc. are governed by its microstructural design. However, the ability to manipulate the TBC microstructure through appropriate control of spraying conditions is intimately dependent on a complete understanding of the mechanism responsible for coating formation. The short residence times (typically of the order of few milliseconds) that are available for the rapid transformation of the precursor solution into a coating, and the inappropriateness of the tools usually used to investigate in-flight particles in conventional plasma spraying to diagnose SPPS, had hampered such an understanding for long. However, studies have now revealed that the properties of SPPS coatings can be correlated with mixture radially fed into a $9 \mathrm{MB}$ Metco plasma spray torch and sprayed at $46 \mathrm{~kW}$ power and $50 \mathrm{~mm}$ spray distance (Ref 53)

the in situ particle generation and the subsequent formation of splats when these particles impact the substrate (Ref 48). It has further been realized that, apart from the particles formed in-flight, any unpyrolyzed precursor impacting the preheated substrate is another crucial factor influencing the microstructure of the coating formed. The gradually improved understanding of the SPPS process in general has been well summarized in some excellent reviews that have periodically appeared in literature (Ref 49-52).

In SPPS coatings, the presence of through-thickness vertical cracks in the deposited TBCs is critical for enhancing their strain tolerance and, thereby, their performance and durability. A microstructure with high segmented crack density (number of vertically aligned cracks per $\mathrm{mm}$ across a defined cross section) and moderate porosity has been reported to yield superior properties with good thermal cycling performance (Ref 53, 54). It has also been proposed that evolution of the vertical cracks can be attributed to pyrolytic stresses resulting from precursor decomposition at the substrate (Ref 53). Based on the above understanding of the SPPS process, it has been demonstrated that varying the solution precursor flow rate provides an ideal pathway for controlling the coating microstructure in SPPS YSZ coatings. Since the pyrolytic stress can vary depending upon the amount of unpyrolyzed precursor incorporated in the coating and the plasma heat input available for complete/partial decomposition of the precursor, suitable control of the spray conditions process variables can be exploited to ensure vertical crack formation in SPPS YSZ coatings.

Figure 9 illustrates typical micrographs of YSZ particles generated in-flight and splats formed upon impact of these particles with the substrate. A vertically cracked YSZ coating obtained by controlling the spray conditions is also shown. The improved understanding of the process has laid down the foundation to explain the associated mechanisms (Ref 53) as well as further expand the utility of the SPPS process (Ref 55-57).

The enhanced appreciation of the process emerging from the above studies provides an ideal foundation to 
exploit the wide-ranging benefits of the SPPS technique and its versatility. Exciting prospects for hybrid processing, combining the SPPS method with conventional powderbased plasma spraying, to yield novel microstructures and superior properties have already been shown (Ref 58).

\section{Conclusions}

Liquid feedstock plasma spraying, comprising solution precursor plasma spraying (SPPS) and suspension plasma spraying (SPS), has been the subject of considerable research interest in recent times. This has been mainly in recognition of the fact that it offers significant advantages, such as generation of nano-structured coatings, permitting better control over coating chemistry and yielding interesting microstructural features like columnar structures/ vertical cracks, nano-sized pores, fine splats, while overcoming challenges associated with feeding fine powders. Various studies carried out so far have led to a more complete knowledge of mechanisms associated with coating formation, as well as process-microstructure relationships in case of both SPS and SPPS, to permit greater control. Modeling efforts have also enabled assessment of influence of inherent coating defects such as pores and cracks on thermal-mechanical properties, although the complex interplay between pore coarsening, sintering and crystallite size growth during high temperature exposure in governing thermal properties needs further investigation. The utility of the SPS and SPPS techniques to conveniently enable deposition of coatings with various architectures and utilizing new chemistries has already been demonstrated. In this context, multilayer coatings combining pyrochlores such as gadolinium zirconate with YSZ have potential to augment thermal cyclic life, better combat CMAS attack and suppress excessive erosion. Thus, the solution-based plasma spray processes clearly hold particular promise for deposition of advanced TBC systems.

Open Access This article is distributed under the terms of the Creative Commons Attribution 4.0 International License (http://crea tivecommons.org/licenses/by/4.0/), which permits unrestricted use, distribution, and reproduction in any medium, provided you give appropriate credit to the original author(s) and the source, provide a link to the Creative Commons license, and indicate if changes were made.

\section{References}

1. M. Oechsner, TBC Systems for Gas Turbine Applications: Status and Challenges (Plenary talk), in Conference Proceedings of the Turbine Forum 2012-Advanced Coatings for High Temperatures, http://www.forumt.com, 25-28 May, 2012, Nice, France
2. D. Zhu and R. Miller, Thermal Conductivity and Elastic Modulus Evolution of Thermal Barrier Coatings Under High Heat Flux Conditions, J. Therm. Spray Technol., 2000, 9(2), p 175-180

3. M. Gupta, G. Dwivedi, P. Nylen, A. Vackel, and S. Sampath, An Experimental Study of Microstructure-Property Relationships in Thermal Barrier Coatings, J. Therm. Spray Technol., 2013, 22(5), p 659-670

4. N. Curry, N. Markocsan, L. Östergren, X.-H. Li, and M. Dorfman, Evaluation of the Lifetime and Thermal Conductivity of Dysprosia-Stabilised Thermal Barrier Coating Systems", J. Therm. Spray Technol., 2013, 22(6), p 864-872

5. Y. Liu, T. Nakamura, V. Srinivasan, A. Vaidya, A. Gouldstone, and S. Sampath, Non-linear Elastic Properties of Plasma-Sprayed Zirconia Coatings and Associated Relationships with Processing Conditions, Acta Mater., 2007, 55, p 4667-4678

6. A. Feuerstein, J. Knapp, T. Taylor, A. Ashary, A. Bolcavage, and N. Hitchman, Technical and Economical Aspects of Current Thermal Barrier Coating Systems for Gas Turbine Engines by Thermal Spray and EBPVD, J. Therm. Spray Technol., 2008, 17(2), p 199-213

7. H. Kassner, R. Siegert, D. Hathiramani, R. Vassen, and D. Stoever, Application of Suspension Plasma Spraying (SPS) for Manufacture of Ceramic Coatings, J. Therm. Spray Technol., 2008, 17(1), p 115-123

8. N. Curry, K. VanEvery, T. Snyder, and N. Markocsan, Thermal Conductivity Analysis and Lifetime Testing of Suspension Plasma-Sprayed Thermal Barrier Coatings, Coatings, 2014, 4(3), p 630-650

9. R. Vassen, A. Stuke, and D. Stöver, Recent Developments in the Field of Thermal Barrier Coatings, J. Therm. Spray Technol., 2009, 18(2), p 181-186

10. M. Gupta, Design of Thermal Barrier Coatings-A Modelling Approach, Springer Briefs in Materials, Springer International Publishing, New York, 2015

11. M. Gupta, N. Curry, P. Nylén, N. Markocsan, and R. Vassen, Design of Next Generation Thermal Barrier Coatings - Experiments and Modelling, Surf. Coat. Technol., 2013, 220, p 20-26

12. M. Gupta, P. Nylén, and J. Wigren, A Modelling Approach to Design of Microstructures in Thermal Barrier Coatings, J. Ceram. Sci. Technol., 2013, 4(2), p 85-92

13. P. Fauchais, C. Delbos, V. Rat, J.F. Coudert, J. Fazilleau, and B. Pateyron, Phenomena Involved in Suspension Plasma Spraying Part 1: Suspension Injection and Behavior, Plasma Chem. Plasma Process., 2006, 26(4), p 371-391

14. P. Fauchais, R. Etchart-Salas, V. Rat, J.F. Coudert, N. Caron, and K. Wittmann-Teneze, Parameters Controlling Liquid Plasma Spraying Solutions, Sols, or Suspensions, J. Therm. Spray Technol., 2008, 17(1), p 31-59

15. K. VanEvery, M.J.M. Krane, R.W. Trice, H. Wang, W. Porter, M. Besser, D. Sordelet, J. Ilavsky, and J. Almer, Column Formation in Suspension Plasma-Sprayed Coatings and Resultant Thermal Properties, J. Therm. Spray Technol., 2011, 20(4), p 817-828

16. J. Oberste-Berghaus, S. Bouaricha, J.-G. Legoux, and C. Moreau, Injection Conditions and in-Flight Particle States in Suspension Plasma Spraying of Alumina and Zirconia Nano-Ceramics, Thermal Spray 2005: Thermal Spray Connects: Explore Its Surfacing Potential!, ed. by E. Lugscheider, May 2-4, (Basel, Switzerland, 2005), DVS-German Welding Society, 2005

17. A. Ganvir, N. Curry, S. Björklund, N. Markocsan, and P. Nylén, Characterization of Microstructure and Thermal Properties of YSZ Coatings Obtained by Axial Suspension Plasma Spraying (ASPS), J. Therm. Spray Technol., 2015, 24(7), p 1195-1204

18. A. Ganvir, N. Markocsan, and S. Joshi, Influence of Isothermal Heat Treatment on Porosity and Crystallite Size in Axial Suspension Plasma Sprayed Thermal Barrier Coatings for Gas 
Turbine Applications, Coatings, 2017, 7(1). doi:10.3390/ coatings 7010004

19. N. Curry, Z. Tang, N. Markocsan, and P. Nylen, Influence of Bond Coat Surface Roughness on the Structure of Axial Suspension Plasma Spray Thermal Barrier Coatings - Thermal and Lifetime Performance, Surf. Coat. Technol., 2015, 268, p 15-23

20. N. Markocsan, A. Ganvir, and P. Newbatt, Influence of Coating Morphology on Thermal Properties and Lifetime of Axial Suspension Plasma Sprayed Thermal Barrier Coatings, invited talk at the "Thermal Spray of Suspensions \& Solutions Symposium (TS4)", Montreal, 2-3 December, 2015

21. D. Stöver, G. Pracht, H. Lehmann, M. Dietrich, J.-E. Döring, and R. Vaßen, New Material Concepts for the Next Generation of Plasma-Sprayed Thermal Barrier Coatings, J. Therm. Spray Technol., 2004, 13(1), p 76-83

22. D.R. Clarke and S.R. Phillpot, Thermal Barrier Coating Materials, Mater. Today, 2005, 8(6), p 22-29

23. R. Vassen, X. Cao, F. Tietz, D. Basu, and D. Stöver, Zirconates as New Materials for Thermal Barrier Coatings, J. Am. Ceram. Soc., 2000, 83(8), p 2023-2028

24. J. Wu, X. Wei, N.P. Padture, P.G. Klemens, M. Gell, E. García, P. Miranzo, and M.I. Osendi, Low Thermal Conductivity RareEarth Zirconates for Possible Thermal-Barrier Coatings Application, J. Am. Ceram. Soc., 2002, 85(12), p 3031-3035

25. Z. Xu, L. He, R. Mu, S. He, and X. Cao, Preparation and Characterization of $\mathrm{La}_{2} \mathrm{Zr}_{2} \mathrm{O}_{7}$ Coating with the Addition of $\mathrm{Y}_{2} \mathrm{O}_{3}$ by EB-PVD, J. Alloys Compd., 2010, 492(1-2), p 701-705

26. G. Mauer, M.O. Jarligo, D.E. Mack, and R. Vaßen, Plasma-Sprayed Thermal Barrier Coatings: New Materials, Processing Issues, and Solutions, J. Therm. Spray Technol., 2013, 22(5), p 646-658

27. S. Krämer, J. Yang, and C.G. Levi, Infiltration-Inhibiting Reaction of Gadolinium Zirconate Thermal Barrier Coatings with CMAS Melts, J. Am. Ceram. Soc., 2008, 91, p 576-583

28. S.R. Choi, N.P. Bansal, and D. Zhu, Mechanical and Thermal Properties of Advanced Oxide Materials for Higher-Temperature Coatings Applications, in Advances in Ceramic Coatings and Ceramic-Metal Systems: A Collection of Papers Presented at the 29th International Conference on Advanced Ceramics and Composites, Jan 23-28, 2005, Cocoa Beach, FL, Ceramic Engineering and Science Proceedings, vol. 26, no. 3 (Wiley, 2005)

29. E. Bakan, D.E. Mack, G. Mauer, and R. Vaßen, Gadolinium Zirconate/YSZ Thermal Barrier Coatings: Plasma Spraying, Microstructure, and Thermal Cycling Behavior, J. Am. Ceram. Soc., 2014, 97(12), p 4045-4051

30. X. Zhong, H. Zhao, X. Zhou, C. Liu, L. Wang, F. Shao, K. Yang, S. Tao, and C. Ding, Thermal Shock Behavior of Toughened Gadolinium Zirconate/YSZ Double-Ceramic-Layered Thermal Barrier Coating, J. Alloys Compd., 2014, 593, p 50-55

31. R.M. Leckie, S. Krämer, M. Rühle, and C.G. Levi, Thermochemical Compatibility Between Alumina and $\mathrm{Zro}_{2}-\mathrm{Gdo}_{3 / 2}$ Thermal Barrier Coatings, Acta Mater., 2005, 53(11), p 32813292

32. X. Zhong, H. Zhao, C. Liu, L. Wang, F. Shao, X. Zhou, S. Tao, and C. Ding, Improvement in Thermal Shock Resistance of Gadolinium Zirconate Coating by Addition of Nanostructured Yttria Partially-Stabilized Zirconia, Ceram. Int., 2015, 41(6), p 7318-7324

33. K.S. Lee, D.H. Lee, and T.W. Kim, Microstructure Controls in Gadolinium Zirconate/YSZ Double Layers and Their Properties, J. Ceram. Soc. Jpn., 2014, 122(1428), p 668-673

34. E. Bakan, D.E. Mack, G. Mauer, R. Mücke, and R. Vaßen, Porosity-Property Relationships of Plasma-Sprayed $\mathrm{Gd}_{2} \mathrm{Zr}_{2} \mathrm{O}_{7} /$ YSZ Thermal Barrier Coatings, J. Am. Ceram. Soc., 2015, 98(8), p 2647-2654

35. E. Bakan, D.E. Mack, G. Mauer, and R. Vaßen, Gadolinium Zirconate/YSZ Thermal Barrier Coatings: Plasma Spraying,
Microstructure and Thermal Cycling Behavior, J. Am. Ceram. Soc., 2014, 97, p 4045-4051

36. S. Mahade, N. Curry, S. Björklund, N. Markocsan, and P. Nylén, Thermal Conductivity And Thermal Cyclic Fatigue Of Multilayered $\mathrm{Gd}_{2} \mathrm{Zr}_{2} \mathrm{O}_{7} / \mathrm{YSZ}$ Thermal Barrier Coatings Processed By Suspension Plasma Spray, Surf. Coat. Technol., 2015, 283, p 329336

37. S. Mahade, R. Li, N. Curry, S. Björklund, N. Markocsan, and P. Nylén, Isothermal Oxidation Behavior of $\mathrm{Gd}_{2} \mathrm{Zr}_{2} \mathrm{O}_{7} / \mathrm{YSZ}$ MultiLayered Thermal Barrier Coatings, Int. J. Appl. Ceram. Technol., 2016, 13(3), p 443-450

38. S. Mahade, N. Curry, S. Björklund, N. Markocsan, P. Nylén, and R. Vaßen, Erosion Behavior of Gadolinium Zirconate/YSZ Multi-Layered Thermal Barrier Coatings Deposited by Suspension Plasma Spray, in Thermal Spray 2016: Proceedings of the International Thermal Spray Conference (Shanghai, P.R. China), May 10-12, 2016, DVS-Berichte vol. 324, DVS Media GmbH, Düsseldorf, 2016, pp 343-348

39. S. Mahade, N. Curry, S. Björklund, N. Markocsan, P. Nylén, and R. Vaßen, Functional Performance of $\mathrm{Gd}_{2} \mathrm{Zr}_{2} \mathrm{O}_{7} / \mathrm{YSZ}$ Multi-layered Thermal Barrier Coatings Deposited by Suspension Plasma Spray, Surf. Coat. Technol., 2017, 318, p 208-216

40. R.J.L. Steenbakker, R.G. Wellman, and J.R. Nicholls, Erosion of Gadolinia Doped EB-PVD TBCs, Surf. Coat. Technol., 2006, 201, p 2140-2146

41. V. Vishwanathan, G. Dwivedi, and S. Sampath, Engineered Multilayer Thermal Barrier Coatings for Enhanced Durability and Functional Performance, J. Am. Ceram. Soc., 2014, 97, p 2770-2778

42. V. Vishwanathan, G. Dwivedi, and S. Sampath, Multilayer, Multimaterial Thermal Barrier Coating Systems: Design, Synthesis and Performance Assessment, J. Am. Ceram. Soc., 2015, 97, p 1769-1777

43. L. Xie, X. Ma, E.H. Jordan, N.P. Padture, D.T. Xiao, and M. Gell, Identification of Coating Deposition Mechanisms in the SolutionPrecursor Plasma-Spray Process Using Model Spray Experiments, Mater. Sci. Eng. A, 2003, 362, p 204-212

44. D. Chen, E.H. Jordan, and M. Gell, The Solution Precursor Plasma Spray Coatings: Influence of Solvent Type, Plasma Chem. Plasma Process., 2009, 30, p 111-119

45. P. Fauchais, V. Rat, J.F. Coudert, R. Etchart-Salas, and G. Montavon, Operating Parameters for Suspension and Solution Plasma-Spray Coatings, Surf. Coat. Technol., 2008, 202, p 43094317

46. M. Gell, E.H. Jordan, M. Teicholz, B.M. Cetegen, N.P. Padture, L. Xie, D. Chen, X. Ma, and J. Roth, Thermal Barrier Coatings Made by the Solution Precursor Plasma Spray Process, J. Therm. Spray Technol., 2008, 17(1), p 124-135

47. P. Fauchais and G. Montavon, Latest Developments in Suspension and Liquid Precursor Thermal Spraying, J. Therm. Spray Technol., 2010, 19(1-2), p 226-239

48. G. Sivakumar, R.O. Dusane, and S.V. Joshi, In Situ Particle Generation and Splat Formation During Solution Precursor Plasma Spraying of Yttria-Stabilized Zirconia Coatings, J. Am. Ceram. Soc., 2011, 94(12), p 4191-4199

49. L. Pawlowski, Suspension and Solution Thermal Spray Coatings, Surf. Coat. Technol., 2009, 203, p 2807-2829

50. A. Killinger, R. Gadow, G. Mauer, A. Guignard, R. Vaßen, and D. Stöver, Review of New Developments in Suspension and Solution Precursor Thermal Spray Processes, J. Therm. Spray Technol., 2011, 20, p 677-695

51. P. Fauchais, M. Vardelle, S. Goutier, and A. Vardelle, Key Challenges and Opportunities in Suspension and Solution Plasma Spraying, Plasma Chem. Plasma Process., 2014, 35, p 511-525

52. E.H. Jordan, C. Jiang, and M. Gell, The Solution Precursor Plasma Spray (SPPS) Process: A Review with Energy Considerations, J. Therm. Spray Technol., 2015, 24, p 1153-1165 
53. G. Sivakumar, R.O. Dusane, and S.V. Joshi, Understanding the Formation of Vertical Cracks in Solution Precursor Plasma Sprayed Yttria-Stabilized Zirconia Coatings, J. Am. Cer. Soc., 2014, 97(11), p 3396-3406

54. E.H. Jordan, L. Xie, M. Gell, N.P. Padture, B. Cetegen, A. Ozturk, J. Roth, T.D. Xiao, and P.E.C. Bryant, Superior Thermal Barrier Coatings Using Solution Precursor Plasma Spray, J. Therm. Spray Technol., 2004, 13, p 57-65

55. G. Sivakumar, R.O. Dusane, and S.V. Joshi, A Novel Approach to Process Phase Pure $\alpha-\mathrm{Al}_{2} \mathrm{O}_{3}$ Coatings by Solution Precursor Plasma Spraying, J. Eur. Ceram. Soc., 2013, 33, p 2823-2829
56. A. Vasiliev, N. Padture, and X. Ma, Coatings of Metastable Ceramics Deposited by Solution-Precursor Plasma spray: I. Binary $\mathrm{ZrO}_{2}-\mathrm{Al}_{2} \mathrm{O}_{3}$ System, Acta Mater., 2006, 54, p 4913-4920

57. A. Vasiliev and N. Padture, Coatings of Metastable Ceramics Deposited by Solution-Precursor Plasma Spray: II. Ternary $\mathrm{ZrO}_{2}-\mathrm{Y}_{2} \mathrm{O}_{3}-\mathrm{Al}_{2} \mathrm{O}_{3}$ System, Acta Mater., 2006, 54, p 4921-4928

58. S.V. Joshi, G. Sivakumar, T. Raghuveer, and R.O. Dusane, Hybrid Plasma-Sprayed Thermal Barrier Coatings Using Powder and Solution Precursor Feedstock, J. Therm. Spray Technol., 2014, 23(4), p 616-624 